Article

\title{
Conversion of Oximes to Carbonyl Compounds by Triscetylpyridinium Tetrakis(oxodiperoxotungsto) Phosphate (PCWP)-mediated Oxidation with Hydrogen Peroxide
}

\author{
Francesco P. Ballistreri *, Ugo Chiacchio, Antonio Rescifina*, Gaetano Tomaselli and Rosa M. \\ Toscano
}

Dipartimento di Scienze Chimiche, Università di Catania, Viale Andrea Doria 6, Catania 95125, Italy; E-mails: uchiacchio@unict.it; gtomaselli@unict.it; rmtoscano@unict.it

* Authors to whom correspondence should be addressed; E-mails: fballistreri@unict.it (Francesco Ballistreri) and arescifina@unict.it (Antonio Rescifina)

Received: 29 April 2008; in revised form: 12 May 2008 / Accepted: 15 May 2008 / Published: 1 June 2008

\begin{abstract}
Aromatic and aliphatic oximes have been deoximated in chloroform-water to the corresponding aldehydes with dilute hydrogen peroxide and triscetylpyridinium tetrakis (oxodiperoxotungsto) phosphate as catalyst. The presence of dipolarophiles in the reaction mixtures allows a competitive reaction that converts oximes into isoxazole and isoxazoline derivatives via the intermediate formation of nitrile oxide species.
\end{abstract}

Keywords: Oxidation of oximes; oxodiperoxotungsto complex; 1,3-dipolar cycloaddition; nitrile oxides; aldehydes.

\section{Introduction}

Oximes are frequently used as carbonyl protector groups [1] from which the parent carbonyl compounds must be regenerated. Regeneration of the carbonyl compound requires the use of soft reagents that will cleave the oxime bond without modification under mild reaction conditions. 
Furthermore, since oximes can also be prepared from non-carbonyl compounds, the generation of carbonyl compounds from them provides an alternative method for the preparation of aldehydes and ketones [2-5]. The traditional hydrolytic method for deprotection of oximes requires the use of strong acids and often results in low yields due to the formation of polymeric by-products, so a number of alternative methods have been developed. Some previously reported carbonyl compound deoximation methods involve oxidative or reductive protocols using, for example, pyridinium dichromate, $t$-butylhydroperoxide, and so on. [6,7]. Some of these reactions have different disadvantages such as long reaction times, difficulties in isolation of products and the possibility of explosions due to the presence of unstable compounds produced by strong oxidative reagents. Many oxidative deoximation methods of aldoximes cited in the literature give low yields of aldehydes due to their over-oxidation to acids.

$\mathrm{Mo}(\mathrm{VI})$ and $\mathrm{W}(\mathrm{VI})$ peroxopolyoxo complexes, whose general formula is $\mathrm{Q}_{3}{ }^{+}\left\{\mathrm{PO}_{4}\left[\mathrm{MO}\left(\mathrm{O}_{2}\right)_{2}\right]_{4}\right\}^{3-}$, are one of the most promising group of catalysts for the selective transfer oxygen to organic substrates [8-9]. They can be stoichiometrically used as oxidant agents or as catalysts in the oxidation processes employing dilute hydrogen peroxide. Lacunary polyoxotungstates have been also recently been screened as catalysts for $\mathrm{H}_{2} \mathrm{O}_{2}$ oxidations under microwave irradiation [10]. Hydrogen peroxide as oxidant has the great advantage to generate only water as by-product. It has a high content of active oxygen and it is less expensive than organic peroxides and peracids. Another advantage of using these salts as oxidants comes from the possibility that the counteraction $\mathrm{Q}^{+}$itself acts as a phase transfer agent when $\mathrm{Q}^{+}$represents a suitable ammonium salt. In this paper we wish to report the oxidative deprotection reaction of oximes with hydrogen peroxide mediated by triscetylpyridinium tetrakis(oxodiperoxotungsto) phosphate as catalyst to yield the corresponding carbonyl compounds under mild conditions and high yields.

\section{Results and Discussion}

Aromatic and aliphatic oximes 1 treated in water-chloroform at $30{ }^{\circ} \mathrm{C}$ with dilute hydrogen peroxide (35\%, v/v) and $1 \mathrm{~mol} \%$ of $\left[\mathrm{C}_{5} \mathrm{H}_{5} \mathrm{~N}^{+}\left(\mathrm{CH}_{2}\right)_{14} \mathrm{CH}_{3}\right]_{3}\left\{\mathrm{PO}_{4}\left[\mathrm{WO}\left(\mathrm{O}_{2}\right)_{2}\right]_{4}\right\}^{3-}$ (PCWP), used as catalyst, have been transformed to carbonyl compounds 2 (Table 1 ).

Table 1. Deoximation of aldoximes 1 by oxidation with diluted hydrogen peroxide and PCWP ${ }^{\text {a }}$

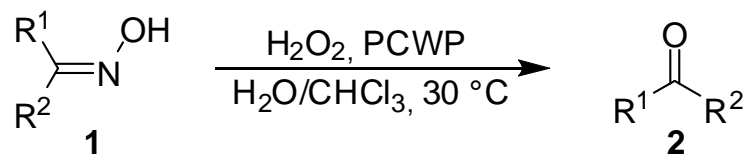

\begin{tabular}{cllccc}
\hline Oxime & $\mathbf{R}^{\mathbf{1}}$ & $\mathbf{R}^{\mathbf{2}}$ & Time (min.) & Conversion (\%) & Yield (\%) $^{\mathrm{b}, \mathrm{c}}$ \\
\hline 1a & $\mathrm{C}_{6} \mathrm{H}_{5}$ & $\mathrm{H}$ & 80 & 90 & 100 \\
1b & $p-\mathrm{Cl}-\mathrm{C}_{6} \mathrm{H}_{4}$ & $\mathrm{H}$ & 70 & 95 & 100 \\
1c & $\mathrm{C}_{6} \mathrm{H}_{5}$ & $\mathrm{CH}_{3}$ & 90 & 80 & 95 \\
1d & $\mathrm{CH}(\mathrm{Me})(\mathrm{Et})$ & $\mathrm{H}$ & 60 & 95 & 70 \\
1e & $n-\mathrm{C}_{7} \mathrm{H}_{15}$ & $\mathrm{H}$ & 60 & 95 & 70 \\
1f & \multicolumn{2}{c}{$-\left(\mathrm{C}_{5} \mathrm{H}_{10}\right)-$} & 90 & 85 & 93 \\
\hline
\end{tabular}

${ }^{\mathrm{a}}$ All the reactions have been performed in $\mathrm{CHCl}_{3} / \mathrm{H}_{2} \mathrm{O}$ at $30{ }^{\circ} \mathrm{C}$ employing [Oximes] $=2.5 \mathrm{mmol} ;\left[\mathrm{H}_{2} \mathrm{O}_{2}\right.$ ] $=20$ mmol and $\left[\right.$ PCWP] $=0.025$ mmol. ${ }^{\mathrm{b}}$ Isolated yields. ${ }^{\mathrm{c}}$ Identities of compounds have been confirmed by comparison of their MS and ${ }^{1} \mathrm{H}-\mathrm{NMR}$ spectra with those of authentic samples. 
The results listed in Table 1 indicate that the reaction is successful for a variety of aliphatic and aromatic oximes. Moreover, the obtained results suggest that aldoximes are deprotected relatively faster than ketoximes.

We also explored the possibility of generating nitrile oxides intermediates for the preparation of isoxazole and isoxazoline derivatives via 1,3-dipolar cycloaddition [11,12], to further expand the synthetic utility of the PCWP oxidation of aldoximes. $\mathrm{N}, \mathrm{O}$-Heterocycles are considered privileged structures in medicinal chemistry, as they show a wide spectrum of biological activities and have been used as antimitotic agents, antiviral compounds, antimicotics and so on [13-14]. Moreover, these compounds have several synthetically useful functionalities, masked in the rings. These functionalities can be released through ring cleavage giving easy access to a variety of open chain derivatives which are differently functionalized [15]. Thus, the reaction in chloroform-water of aldoximes 1a,d, used as model compounds, and treated with dilute hydrogen peroxide (35\%, v/v) and $1 \mathrm{~mol} \%$ of $\left[\mathrm{C}_{5} \mathrm{H}_{5} \mathrm{~N}^{+}\left(\mathrm{CH}_{2}\right)_{14} \mathrm{CH}_{3}\right]_{3}\left\{\mathrm{PO}_{4}\left[\mathrm{WO}\left(\mathrm{O}_{2}\right)_{2}\right]_{4}\right\}^{3-}$ (PCWP), used as catalyst, at $40{ }^{\circ} \mathrm{C}$ in the presence of alkenes 3 (1 equiv.) or alkynes 4 (2.5 equiv.), produced isoxazolines 5 or isoxazoles 6 and 7, respectively, along with variable amounts of aldehydes $\mathbf{2 a , d}$ (Scheme 1, Table 2).

Scheme 1.
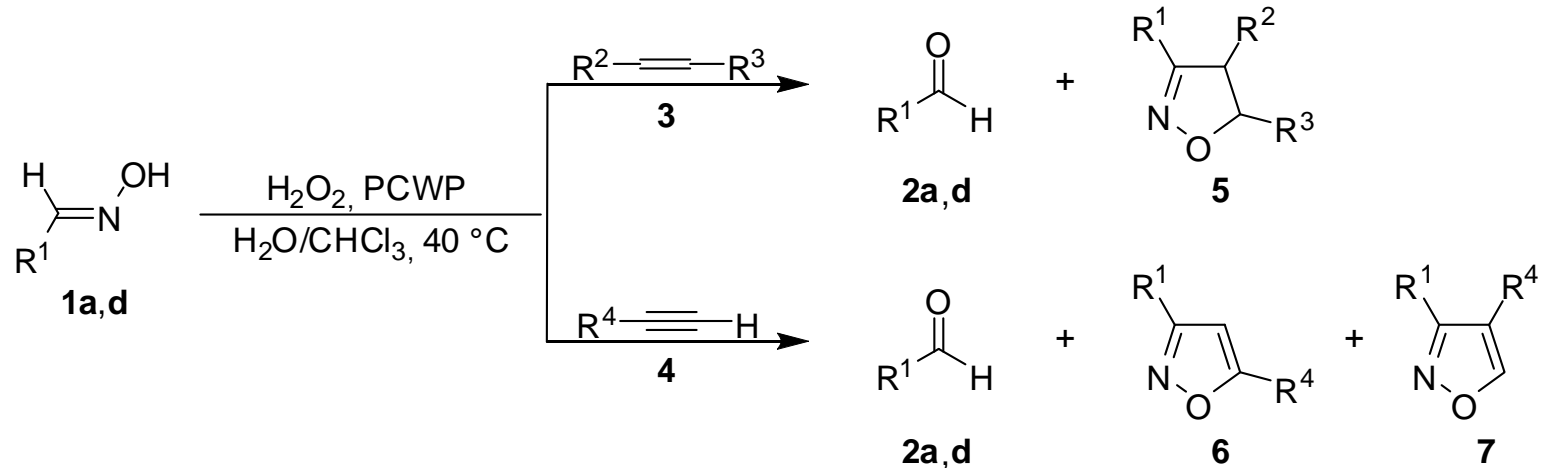

Table 2. Preparation of isoxazole and isoxazoline derivatives by aldoximes oxidation in the presence of alkenes or alkynes ${ }^{a}$.

\begin{tabular}{|c|c|c|c|c|c|c|c|c|c|c|}
\hline \multirow{2}{*}{ Entry } & \multirow{2}{*}{$\mathbf{R}^{1}$} & \multirow{2}{*}{$\mathbf{R}^{2}$} & \multirow{2}{*}{$\mathbf{R}^{3}$} & \multirow{2}{*}{$\mathbf{R}^{4}$} & \multirow{2}{*}{$\begin{array}{c}\text { Time } \\
\text { (h) }\end{array}$} & \multirow{2}{*}{$\begin{array}{c}\text { Conv. } \\
(\%)\end{array}$} & \multicolumn{4}{|c|}{ Yields, $(\%)^{b, c}$} \\
\hline & & & & & & & 2 & 5 & 6 & 7 \\
\hline 1 & $\mathrm{C}_{6} \mathrm{H}_{5}$ & $\mathrm{H}$ & $\mathrm{CH}_{3}\left(\mathrm{CH}_{2}\right)_{5}$ & & 9 & 84 & 62 & 17 & & \\
\hline 2 & $\mathrm{CH}(\mathrm{Me})(\mathrm{Et})$ & $\mathrm{H}$ & $\mathrm{CH}_{3}\left(\mathrm{CH}_{2}\right)_{5}$ & & 5 & 89 & 56 & 6 & & \\
\hline 3 & $\mathrm{C}_{6} \mathrm{H}_{5}{ }^{\mathrm{d}}$ & $\mathrm{CO}_{2} \mathrm{Me}$ & $\mathrm{CO}_{2} \mathrm{Me}$ & & 9 & 81 & 43 & 46 & & \\
\hline 4 & $\mathrm{CH}(\mathrm{Me})(\mathrm{Et})^{\mathrm{e}}$ & $\mathrm{CO}_{2} \mathrm{Me}$ & $\mathrm{CO}_{2} \mathrm{Me}$ & & 6 & 100 & 30 & 30 & & \\
\hline 5 & $\mathrm{C}_{6} \mathrm{H}_{5}$ & & & $\mathrm{C}_{6} \mathrm{H}_{5}$ & 16 & 71 & 67 & & 28 & \\
\hline 6 & $\mathrm{CH}(\mathrm{Me})(\mathrm{Et})$ & & & $\mathrm{C}_{6} \mathrm{H}_{5}$ & 6.5 & 90 & 49 & & 9 & \\
\hline 7 & $\mathrm{C}_{6} \mathrm{H}_{5}$ & & & $\mathrm{CH}_{3}\left(\mathrm{CH}_{2}\right)_{5}$ & 6.5 & 83 & 49 & & 32 & \\
\hline 8 & $\mathrm{CH}(\mathrm{Me})(\mathrm{Et})$ & & & $\mathrm{CH}_{3}\left(\mathrm{CH}_{2}\right)_{5}$ & 3 & 88 & 33 & & 5 & \\
\hline 9 & $\mathrm{C}_{6} \mathrm{H}_{5}$ & & & $\mathrm{CO}_{2} \mathrm{Me}$ & 8 & 86 & 30 & & 42 & 13 \\
\hline 10 & $\mathrm{CH}(\mathrm{Me})(\mathrm{Et})$ & & & $\mathrm{CO}_{2} \mathrm{Me}$ & 3 & 100 & 43 & & 25 & 8 \\
\hline
\end{tabular}

${ }^{\mathrm{a}} \mathrm{All}$ the reactions have been performed in $\mathrm{CHCl}_{3} / \mathrm{H}_{2} \mathrm{O}$ at $40{ }^{\circ} \mathrm{C}$ employing [Oximes] $\left.=2.5 \mathrm{mmol} ; \mathrm{H}_{2} \mathrm{O}_{2}\right]=20$ mmol and $[\mathrm{PCWP}]=0.025$ mmol. ${ }^{\mathrm{b}}$ Isolated yields. ${ }^{\mathrm{C}}$ Identities of the compounds have been obtained comparing their MS and ${ }^{1} \mathrm{H}$-NMR spectra with those of authentic samples. ${ }^{\mathrm{d}}$ The reaction is stereospecific; fumarate gave $E$ adduct whereas maleate gave $Z$-adduct. ${ }^{\mathrm{e}}$ The reaction has been performed with fumarate. 
The results indicate that the aldehydes are the main products of the reaction, except for entries 3 and 4 (cycloadduct-aldehyde ratio 1:1) and entry 9 (cycloadduct-aldehyde ratio 1.8:1). The stereochemistry of the cycloadducts depends on the stereochemistry of the dipolarophiles (entry 3 ) - the $E$-adduct was obtained using fumarate and the Z-ones has been obtained with maleate. Moreover, all the experiments show that aromatic oximes lead to a higher yield of cycloadduct than aliphatic ones, and the presence of electron-withdrawing groups on the dipolarophile moiety increases the yield of cycloadduct (entries 3, 4, 9 and 10). The formation of isoxazole derivatives 5-7 supports the intermediate formation of the corresponding nitrile oxide [16]. In fact, the reaction of $\mathrm{C}_{6} \mathrm{H}_{5} \mathrm{CH}=\mathrm{NOH}$ (2.5 mmol) with $\mathrm{H}_{2} \mathrm{O}_{2}$ (20 $\mathrm{mmol})$ and PCWP (0.025 mmol) in $\mathrm{CHCl}_{3}$ at $40{ }^{\circ} \mathrm{C}$, in the absence of dipolarophiles gives as main product benzaldehyde, along with a small amount of diphenylfuroxan. The same reaction followed by IR shows two significative bands: at $2250 \mathrm{~cm}^{-1}$ corresponding to benzonitrile oxide [17], and at 1700 $\mathrm{cm}^{-1}$ associated to benzaldehyde. Furthermore, the data point out that the regioselectivity of the cycloaddition process is in accordance with both steric and frontier molecular orbital interactions of the reagents [16].

At this stage it is hard to suggest a mechanistic pathway for this reaction. It is known that peroxopolyoxocomplexes such as PCWP behave as electrophilic oxidants $[18,19]$ and therefore the oxidation reaction might be triggered by a nucleophilic $[18,20]$ attack of the oxime nitrogen-atom to the peroxide oxygen followed by catalytic hydrogen peroxide regeneration of the oxidant and by subsequent steps for the products formation (Scheme 2). However, it is also known that PCWP is also a good electron acceptor [21,22] and therefore the involvement of electron transfer events cannot be excluded a priori.

Scheme 2.

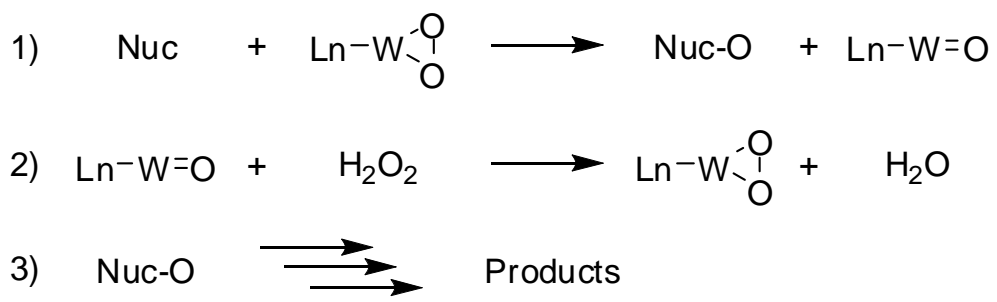

\section{Conclusions}

In summary, aromatic and aliphatic oximes $\mathbf{1}$ can be easily deoximated in water-chloroform to the corresponding aldehydes 2 with dilute hydrogen peroxide $(35 \%, \mathrm{v} / \mathrm{v})$ mediated by $1 \mathrm{~mol} \%$ of $\left[\mathrm{C}_{5} \mathrm{H}_{5} \mathrm{~N}^{+}\left(\mathrm{CH}_{2}\right)_{14} \mathrm{CH}_{3}\right]_{3}\left\{\mathrm{PO}_{4}\left[\mathrm{WO}\left(\mathrm{O}_{2}\right)_{2}\right]_{4}\right\}^{3-}$ (PCWP). The presence in the reaction mixtures of alkenes and alkynes as dipolarophiles allows a competitive reaction path which converts the oximes into isoxazole and isoxazoline derivatives through the intermediate formation of nitrile oxide species. 


\section{Experimental}

\section{General}

Aldoximes, alkynes and alkenes (Aldrich) were distilled or crystallized before use. Chloroform (Carlo Erba, RPE) was distilled over $\mathrm{P}_{4} \mathrm{O}_{10}$, whereas $\mathrm{H}_{2} \mathrm{O}_{2}$ (35\%, v/v) (Carlo Erba, RPE) was used without further purification. ${ }^{1} \mathrm{H}$ - and ${ }^{13} \mathrm{C}-\mathrm{NMR}$ were obtained on a Varian Unity Inova $200 \mathrm{MHz}$ spectrometer operating at 200 and $50 \mathrm{MHz}$, respectively, using $\mathrm{CDCl}_{3}$ as solvent and TMS as internal standard. GLC analyses were carried out on a programmable Perkin-Elmer 8420 gas chromatograph equipped with a flame ionization detector and a 25 m DB-1 capillary column. GC/MS analyses were performed on a Hewlett-Packard model 5890 gas chromatograph, using an HP-1 dimethylpolysiloxane 25 m capillary column, equipped with a Hewlett-Packard MS computerized system Model 5971A, ionization voltage $70 \mathrm{eV}$, electron multiplier $1700 \mathrm{~V}$, ion source temperature $280{ }^{\circ} \mathrm{C}$. IR spectra were recorded on a Perkin-Elmer Paragon 500 FT-IR Spectrometer using potassium bromide discs.

\section{Preparation of triscetylpyridinium tetrakis(diperoxotungsto)phosphate (PCWP)}

To a solution of cetylpyridinium chloride $\left(3.1 \mathrm{mmol}\right.$ ) in $35 \% \mathrm{H}_{2} \mathrm{O}_{2}$ (40 mL) has been added $\mathrm{H}_{3} \mathrm{PW}_{12} \mathrm{O}_{40} \cdot \mathrm{nH}_{2} \mathrm{O}(3 \mathrm{~g})$ in $35 \% \mathrm{H}_{2} \mathrm{O}_{2}(10 \mathrm{~mL})$, and the mixture has been stirred at $40{ }^{\circ} \mathrm{C}$ for $4-5 \mathrm{~h}$. The white precipitate, after filtration, has been washed with water until all the $\mathrm{H}_{2} \mathrm{O}_{2}$ was removed and then dried in vacuo over $\mathrm{P}_{4} \mathrm{O}_{10}$. The IR spectrum $(\mathrm{KBr})$ corresponded to the one reported in the literature [23].

\section{Oxidation and cycloaddition reactions: general procedure for oxidation}

To a warm $\left(30^{\circ} \mathrm{C}\right)$ solution containing PCWP $(0.025 \mathrm{mmol})$ in chloroform $(5 \mathrm{~mL})$ has been added a solution of aldoxime $(2.5 \mathrm{mmol})$ and $\mathrm{H}_{2} \mathrm{O}_{2}(35 \%, 1.8 \mathrm{~mL}, 20 \mathrm{mmol})$. After the addition has been completed, the mixture has been stirred at $30{ }^{\circ} \mathrm{C}$ for an appropriate time, then the organic layer has been separated, washed with a $10 \%$ of aqueous solution of sodium bisulphite and dried over anhydrous sodium sulphate. The solvent has been removed under reduced pressure to leave a thick oil, which has been subjected to silica gel chromatography using a 30\% ethyl acetate/cyclohexane mixture as eluent. The ${ }^{1} \mathrm{H}$-NMR spectra of aldehydes $\mathbf{2 a}-\mathbf{f}$ corresponded to the ones reported in the literature.

\section{General procedure for oxidation-cycloaddition}

A solution of aldoxime (2.5 mmol), alkene $(2.5 \mathrm{mmol})$ or alkyne $(7.5 \mathrm{mmol})$ in chloroform $(5 \mathrm{~mL})$ and $\mathrm{H}_{2} \mathrm{O}_{2}$ (35\%, $\left.1.8 \mathrm{~mL}, 20 \mathrm{mmol}\right)$ were added to a warm $\left(40^{\circ} \mathrm{C}\right)$ solution of PCWP $(0.025 \mathrm{mmol})$ in chloroform $(5 \mathrm{~mL})$. After the addition was completd, the mixture was stirred at $40{ }^{\circ} \mathrm{C}$ for an appropriate time, after which the organic layer was separated, washed with a $10 \%$ aqueous solution of sodium bisulphite and finally dried over anhydrous sodium sulphate. The solvent has been removed under reduced pressure to leave a thick oil, which was subjected to silica gel chromatography using a $30 \%$ ethyl acetate/cyclohexane mixture as eluent. The ${ }^{1} \mathrm{H}-\mathrm{NMR}$ and MS spectra, for the compounds obtained 
in entries 1 [24], 3 [25, 26], 5 [27], 7 [28], and 9 [29, 30], corresponded to the ones reported in the literature.

Data for new compounds in Table 2:

(5RS)-3-sec-Butyl-5-hexyl-4,5-dihydroisoxazole (entry 2): Light yellow oil; ${ }^{1} \mathrm{H}-\mathrm{NMR}$ : 0.84-0.89 (m, $6 \mathrm{H}), 1.23$ (d, 3H, $J=6.1 \mathrm{~Hz}$ ), 1.24-1.43 (m, 12H), 2.28 (m, 1H), 2.63 (dd, 1H, $J=8.4$ and $16.5 \mathrm{~Hz}$ ), 3.01 (dd, $1 \mathrm{H}, J=10.2$ and $16.5 \mathrm{~Hz}$ ), 4.49 (m, 1H); ${ }^{13} \mathrm{C}-\mathrm{NMR}$ : 11.8, 14.1, 18.6, 22.7, 26.0, 26.6, 29.0, 31.7, 35.4, 35.6, 38.4, 80.6, 165.8; Anal. calcd. for $\mathrm{C}_{12} \mathrm{H}_{25} \mathrm{NO}$ : C, 73.88; H, 11.92; N, 6.63\%. Found: C, 73.67; H, 11.94; N, 6.62\%.

Dimethyl (4RS,5RS)-3-sec-butyl-4,5-dihydroisoxazole-4,5-dicarboxylate (entry 4): Light yellow oil; ${ }^{1} \mathrm{H}-\mathrm{NMR}: 0.87$ (t, 3H, $\left.J=7.1 \mathrm{~Hz}\right), 1.15$ (d, 3H, $\left.J=6.1 \mathrm{~Hz}\right), 1.18-1.40$ (m, 2H), 2.58 (m, 1H), 3.72 (s, 3H), 3.81 (s, 3H), 4.63 (d, $1 \mathrm{H}, J=5.0 \mathrm{~Hz}$ ), 5.40 (d, 1H, $J=5.0 \mathrm{~Hz}$ ); ${ }^{13} \mathrm{C}-\mathrm{NMR}: 11.8,18.2,25.9,34.8$, 51.6, 52.5, 60.1, 80.8, 165.9, 167.6, 168.2; Anal. calcd. for $\mathrm{C}_{11} \mathrm{H}_{17} \mathrm{NO}_{5}$ : C, 54.31; H, 7.04; N, 5.76\%. Found: C, 54.48; H, 7.05; N, 5.75\%.

3-sec-Butyl-5-phenylisoxazole (entry 6): Light yellow foam; ${ }^{1} \mathrm{H}-\mathrm{NMR}$ : 0.81 (t, 3H, $J=7.1 \mathrm{~Hz}$ ), 1.28 (d, $3 \mathrm{H}, J=6.8 \mathrm{~Hz}), 1.38-1.69(\mathrm{~m}, 2 \mathrm{H}), 2.87(\mathrm{~m}, 1 \mathrm{H}), 6.31(\mathrm{~s}, 1 \mathrm{H}), 7.30-7.78(\mathrm{~m}, 5 \mathrm{H}) ;{ }^{13} \mathrm{C}-\mathrm{NMR}: 12.4$, 20.1, 29.3, 35.6, 102.7, 125.3, 127.8, 131.9, 132.2, 165.4, 167.3; Anal. calcd. for $\mathrm{C}_{13} \mathrm{H}_{15} \mathrm{NO}$ : C, 77.58; H, 7.51; N, 6.96\%. Found: C, 77.35; H, 7.53; N, 6.97\%.

3-sec-Butyl-5-hexylisoxazole (entry 8): Light yellow oil; ${ }^{1} \mathrm{H}-\mathrm{NMR}$ : 0.88 (t, 3H, $J=7.1 \mathrm{~Hz}$ ), 1.23 (d, $3 \mathrm{H}, J=6.1 \mathrm{~Hz}), 1.24-1.43$ (m, 10H), $1.62(\mathrm{~m}, 2 \mathrm{H}), 2.69$ (t, 2H, $J=6.6 \mathrm{~Hz}), 2.81$ (m, 1H), 5.80 (s, 1H); ${ }^{13}$ C-NMR: 11.6, 14.0, 19.5, 22.4, 26.7, 27.4, 28.7, 29.2, 31.4, 33.1, 98.4, 168.3, 173.2; Anal. calcd. for $\mathrm{C}_{13} \mathrm{H}_{23} \mathrm{NO}$ : C, 74.59; H, 11.07; N, 6.69\%. Found: C, 75.76; H, 11.04; N, 6.68\%.

Methyl 3-sec-butylisoxazole-5-carboxylate (entry 10): Light yellow oil; ${ }^{1} \mathrm{H}-\mathrm{NMR}$ : 0.91 (t, 3H, $J=7.3$ $\mathrm{Hz}$ ), 1.31 (d, 3H, $J=7.1 \mathrm{~Hz}), 1.44-1.78$ (m, 2H), 2.95 (m, 1H), 3.96 (s, 3H), $7.03(\mathrm{~s}, 1 \mathrm{H})$; ${ }^{13} \mathrm{C}-\mathrm{NMR}$ : 12.3, 20.4, 30.1, 31.2, 53.1, 112.8, 157.6, 159.4, 171.7; Anal. calcd. for $\mathrm{C}_{9} \mathrm{H}_{13} \mathrm{NO}_{3}$ : C, 59.00; H, 7.15; N, 7.65\%. Found: C, 58.84; H, 7.18; N, 7.63\%.

Methyl 3-sec-butylisoxazole-4-carboxylate. Light yellow oil; ${ }^{1} \mathrm{H}-\mathrm{NMR}$ : 0.93 (t, 3H, $J=7.3 \mathrm{~Hz}$ ), 1.34 (d, 3H, $J=7.1 \mathrm{~Hz}$ ), 1.47-1.81 (m, 2H), 2.97 (m, 1H), 3.86 (s, 3H), 9.02 (s, 1H); ${ }^{13} \mathrm{C}-\mathrm{NMR}: 12.8,20.6$, 29.4, 30.6, 51.1, 112.5, 154.2, 167.5, 172.1; Anal. Calcd. for $\mathrm{C}_{9} \mathrm{H}_{13} \mathrm{NO}_{3}$ : C, 59.00; H, 7.15; N, 7.65\%. Found: C, 59.11; H, 7.13; N, 7.66\%.

\section{Acknowledgements}

We thank MIUR and the University of Catania for financial support. 


\section{References and Notes}

1. Green, T. W.; Wuts, P. G. Protective Groups in Organic Synthesis, $3^{\text {rd }}$ ed.; John Wiley and Sons: New York, 1991.

2. Barton, D. H. R.; Beaton, J. M. A Synthesis of Aldosterone Acetate. J. Am. Chem. Soc. 1961, 83, 4083-4089.

3. Kadzyauskas, P. P.; Zefirov, N. S. Nitrosochlorination of Alkenes. Russ. Chem. Rev. (Engl. Transl.) 1968, 37, 543-550.

4. Mukai, C.; Hanaoka, M. Development of Highly Stereoselective and Regioselective Reactions Based on the Alkyne- $\mathrm{Co}_{2}(\mathrm{CO})_{6}$ Complexes. Synlett 1996, 11-17.

5. Czekelius, C.; Carreira, E. M. Convenient Transformation of Optically Active Nitroalkanes into Chiral Aldoximes and Nitriles. Angew. Chem. Int. Ed. 2005, 44, 612-615.

6. Corsaro, A.; Chiacchio, U.; Pistarà, V. Regeneration of Carbonyl Compounds from the Corresponding Oximes. Synthesis 2001, 1903-1931.

7. Karami, B.; Montazerozohori, M. Tungstate Sulfuric Acid (TSA)/KMnO 4 as a Novel Heterogeneous System for Rapid Deoximation. Molecules 2006, 11, 720-725.

8. Li, G.; Ding, Y.; Wang, J.; Wang, X.; Suo, J. New Progress of Keggin and Wells-Dawson Type Polyoxometalates Catalyze Acid and Oxidative Reactions. J. Mol. Catal. A 2007, 262, 67-76.

9. Ballistreri, F. P.; Chiacchio, U.; Rescifina, A.; Tomaselli, G. A.; Toscano, R. M. One-Flask Transformation of Secondary Amines to Nitrones by Oxidation with Hydrogen Peroxide Mediated by Triscetylpyrydinium Tetrakis Oxodiperoxotungsto-Phosphate (PCWP): Some Mechanistic Considerations. Tetrahedron 1992, 48, 8677-8684.

10. Carraro, M.; Sandei, L.; Sartorel, A.; Scorrano, G.; Tonchio, M. Hybrid Polyoxotungstates as Second-Generation POM-Based Catalysts for Microwave-Assisted $\mathrm{H}_{2} \mathrm{O}_{2}$ Activation. Org. Lett. 2006, 8, 3671-3674.

11. Wakefield, B. J. Product Class 9: Isoxazoles. In: Science of Synthesis; Georg Thieme Verlag: New York, 2002; Vol. 11, Chapter 9; pp. 229-288.

12. Cicchi, S.; Cordero, F. M.; Giomi, D. Progress in Heterocyclic Chemistry; Gribble, G; Joule, J, Eds.; Pergamon Press: Oxford, 2003; Vol. 15, pp. 261-283.

13. Sun, C.-M.; Lin, L.-G.; Yu, H.-J.; Cheng, C.-Y.; Xai, Y.-C.; Chu, C.-W.; Din, Y.-H.; Chau, Y.-P.; Don, M.-Y. Synthesis and Cytotoxic Activities of 4,5-Diarylisoxazoles. Bioorg. Med. Chem. Lett. 2007, 17, 1078-1081.

14. Chiacchio, U.; Balestrieri, B.; Macchi, B.; Iannazzo, D.; Piperno, A.; Rescifina, A.; Romeo, R.; Saglimbeni, M.; Sciortino, M. T.; Valveri, V.; Mastino, A.; Romeo, G. Synthesis of Phosphonated Carbocyclic 2'-Oxa-3'-aza-nucleosides: Novel Inhibitors of Reverse Transcriptase. J. Med. Chem. 2005, 48, 1389-1394.

15. Chiacchio, U.; Rescifina, A.; Romeo, G. In Targets in Heterocyclic Systems: Chemistry and Properties; Attanasi, O. A.; Spinelli, D., eds.; Italian Society of Chemistry: Rome, 1997; Vol. 1, pp. 225-275.

16. Padwa, A. 1,3-Dipolar Cycloaddition Chemistry; John Wiley \& Sons: New York, 1984.

17. Wiley, R. H.; Wakefield, J. Studies on the Chemistry of Aspenwood. VII.1 Further Studies on the Ether Extractives of Commercial Aspen Spent Sulfite Liquor. J. Org. Chem. 1960, 26, 546-551. 
18. Arcoria, A.; Ballistreri, F. P.; Spina, E.; Tomaselli, G. A.; Toscano, R. M. Kinetics of Mechanism of Oxidation of Organic Sulfides and Olefins by a Molybdenum Peroxopolyoxoanion. Gazz. Chim. Ital. 1990, 120, 309-313.

19. Venturello, C.; D’Aloisio, R.; Bart, J. C.; Ricci, M. A New Peroxotungsten Heteropoly Anion with Special Oxidizing Properties: Synthesis and Structure of Tetrahexylammonium Tetra(diperoxotungsto)phosphate(3-). J. Mol. Catal. 1985, 32, 107-110.

20. Di Furia, F.; Modena, G. Mechanism of Oxygen Transfer from Peroxo Species. Pure Appl. Chem. 1982, 54, 1853-1866.

21. Ballistreri, F. P.; Tomaselli, G. A.; Toscano, R. M.; Conte, V.; Di Furia, F. Application of the Thianthrene 5-Oxide Mechanistic Probe to Peroxometal Complexes. J. Am. Chem. Soc. 1991, 113, 6209-6212.

22. Ballistreri, F. P.; Bazzo, A. Tomaselli, G. A.; Toscano, R. M. Reactivity of Peroxopolyoxo Complexes. Oxidation of Thioethers, Alkenes, and Sulfoxides by Tetrahexylammonium Tetrakis(diperoxomolybdo)phosphate. J. Org. Chem. 1992, 57, 7074-7077.

23. Ishii, Y.; Yamawaki, K.; Ura, T.; Yamada, H.; Yoshida, T.; Ogawa, M. Hydrogen Peroxide Oxidation Catalyzed by Heteropoly Acids Combined with Cetylpyridinium Chloride. Epoxidation of Olefins and Allylic Alcohols, Ketonization of Alcohols and Diols, and Oxidative Cleavage of 1,2-Diols and Olefins. J. Org. Chem. 1988, 53, 3587-3593.

24. Cunico, R. F.; Bedell, L. J. Org. Chem. 1983, 48, 2780-2782.

25. Aversa, M. C.; Cum, G.; Crisafulli, M. NMR Spectra of 2-Isoxazolines. II. Cis-trans Isomers of 4,5-Disubstituted 2-Isoxazolines. Gazz. Chim. Ital. 1968, 98, 42-47.

26. (a) Christl, M.; Huisgen, R.; Sustmann, R. 1,3-Dipolar Cycloadditions. 71. Additions of Benzonitrile Oxide to $\alpha, \beta$-Unsaturated Carboxylic Esters. Chem. Ber. 1973, 106, 3275-3290; (b) Rahman, A.; Clapp, Leallyn, B. Thermal Decomposition of the Potassium Salts of Dinitroalkanes. J. Org. Chem. 1976, 41, 122-125.

27. Hansen, T. V.; Wu, P.; Fokin, V. V. One-Pot Copper(I)-Catalyzed Synthesis of 3,5-Disubstituted Isoxazoles. J. Org. Chem. 2005, 70, 7761-7764.

28. Entry 7: Di Nunno, L.; Scilimati, A.; Vitale, P. 5-Hydroxy-3-phenyl-5-vinyl-2-isoxazoline and 3Phenyl-5-vinylisoxazole: Synthesis and Reactivity. Tetrahedron 2005, 61, 11270-11278.

29. Dadiboyena, S.; Xu, J.; Hamme, A. T. Isoxazoles from 1,1-Disubstituted Bromoalkenes. Tetrahedron Lett. 2007, 48, 1295-1298.

30. Leonardi, A.; Motta, G.; Riva, C.; Poggesi, E. Isoxazolecarboxamide Derivatives and their Adrenergic Antagonist Activity. PCT Int. Appl. WO 2001029015, 2001.

Sample Availability: Samples of all compounds are available from the authors.

(C) 2008 by the authors; licensee Molecular Diversity Preservation International, Basel, Switzerland. This article is an open-access article distributed under the terms and conditions of the Creative Commons Attribution license (http://creativecommons.org/licenses/by/3.0/). 